\title{
PEMANFAATAN MINAREX SEBAGAI SECONDARY PLASTICIZER UNTUK PEMBUATAN KOMPON SEPATU BOOT PVC
}

\section{Supraptiningsih}

\section{Abstract}

The purpose of the research is to find out optimum amount of minarex (side product from Pertamina Jakarta) as secondary plasticizer which can be added to PVC compound in order to obtain boots compound conforming to SII 1909-86: Sepatu boot PVC. Research yield is a slah made by hydraulic press machine. $170^{\prime \prime} \mathrm{C}$ and pressure $150 \mathrm{~kg} / \mathrm{cm}^{2}$ and the time must be suitable with the thickness. From various tvpes of minurex used for the research, four of them can be applied as secondary plasticizer at PVC compound for boots which conforms to S/l 1909-89, i.e. minarex C type 2, minarex C type 3, minarex D type 2 and minarex D type 3 for five parts each.

Abstrak

Penelitian ini bertujuan untuk mengetahui jumlah maximum minarex (hasil samping dar Pertamina Jakarta) sebagai secondary plasticizer yang dapat ditambahkan pada kompon Polv Vinvl Chlorida (PVC) agar diperoleh kompon sepatu boot PVC yang memenuht persyaratan SII 1909-86 : Sepatu boot PVC. Hasil penelitian berupa slab yang dicetak menggunakan mesin hydroulic press dengan kondisi suhu $170^{\circ} \mathrm{C}$, tekanan $150 \mathrm{~kg} / \mathrm{cm}^{2}$ dan waktunya disesuaikan dengan ketebalan. Dari berbagai jenis minarex yang dicoba ternyata ada 4 jenis minarex yang dapat digunakan sebagai secondary plasticizer pada kompon PVC untuk sepatu boot yang sesuai SII 1909-86 yaitu minerax C type 2, minerax C type 3, minerax $D$ type 2 dan minarex $D$ type 3 masing-masing sebanyak 5 bagian.

\section{PENDAHULUAN}

Untuk membuat barang-barang plastik, selain diperlukan bahan baku yang berupa resin juga diperlukan bahan-bahan pembantu (additive) dengan jalan mencampur sempurna bahan-bahan tersebut (komponding). Proses komponding merupakan proses pencampuran antara bahan baku plastik dengan bahan penyusun lain yang bertujuan untuk memperoleh kompon plastik homogen yang mempunyai sifat-sifat sesuai dengan yang dikehendaki. (4)

Agar diperoleh sifat-sifat yang diinginkan pada produk akhir maka pada resin plastik harus ditambahkan zat additive, dimana additive harus mempunyai persyaratan antara lain mudah dicampur dengan resin (stabil), daya tahan terhadap panas cukup baik, sifat listrik yang lebih dan tidak menyebabkan korosi pada cetakan. Additive tersebut berupa filler, plasticizer, lubrican, stabilizer dll. (4)

Polivinyl Chlorida (PVC) merupakan polimer plastik golongan thermoplast yang mempunyai sifat-sifat antara lain tahan terhadap air, bahan kimia, udara, listrik 
dan lain-lain. PVC terbuat dari asetilin dan gas hydrogen klorida. Produk-produk PVC yang dihasilkan antara lain : pipa, jas hujan, sepatu boot, botol, sheet, pelapis kawat dan lain-lain.

Sepatu boot PVC dibuat dengan cara injection molding, yaitu suatu proses pembuatan barang plastik dengan menggunakan cetakan dilakukan dengan cara penyuntikan. Sistim injection molding dibagi dalam tahap-tahap : pelunakan, penvuntikan, curing, pendinginan dan pelepasan dari cetakan seria finishing.

Penelitian ini bertujuan untuk mengetahui jumlah maximum minarex sebagai secondary plasticizer yang dapat ditambahkan pada kompon PVC agar diperoleh kompon sepatu boot PVC yang memenuhi persyaratan SII 1909-86, "Sepatu boot PVC".

Pada specifikasi persyaratan mutu Sil 1909-86 tersebut dibagi dalam dua bagian yaitu : bagian atas sepatu dan bagian bawah sepatu (sol).

Pada penelitian ini hasil uji dibandingkan dengan persyaratan mutu untuk (a) keparena jika telah memenuhi persyaratan mutu untuk bagian bawah. berarti persyaratan bagian atas terpenuhi. Pada penelitian ini dicoba dengan menggunakan plasticizer Dioctyl phalat DOP) dengan secondary plasticizer minarex yang merupakan produk samping dan Pertamina.

\section{MATERI DAN METODE}

1. Materi

Bahan-bahan yang digunakan untuk pembuatan kompon sepatu boot meliputi bahan baku dan bahan pembantu (additive). Bahan baku adalah resin Poly Vinyl Chlorida (PVC) suspension dengan bahan pembantu plasticizer Dioctyl Phtalat (DOP) dan substitusi plasticizer (secondary Plasticizer) berupa minarex jenis A, B, $\mathrm{C}$ dan $\mathrm{D}$. Adapun kompon sepatu dibuat dengan formulasi sbb

1. Poly Vinyl Chlorida (PVC) suspension : 100 bagian

: 2 bagian

3. Filler $\mathrm{CaCO} 3 \quad 10$ bagian

4. Lubricant (asam stearat)

5. Zat warna : 0,02 bagian

6. Plasticizer DOP + secondary : 80 bagian

plasticizer (minarex)

7. Jumlah minarex bervariasi

8. jenis minarex bervariasi yaitu :
- Minarex A type 2
Minarex B type 2
Minarex C type 2
Minarex D type 2
Minarex A type 3
Minarex B type 3
Minarex $C$ type 3
- Minarex D type 3

Juga dibuat kompon dengan $\mathrm{O}$ bagian minarex. Dengan demikian terdapat 61 percobaan pembuatan kompon.

\section{Metode}

\subsection{Pembuatan kompon}

Kompon sepatu boot PVC dibuat dengan cara mencampur bahan-bahan sesuai formulasi didalam mixer dan agar lebih homogen dilanjutkan dengan alat two roll mill pada suhu $+50 \mathrm{C}$, dengan ulangan 3 kali. Kompon yang dihasilkan dicetak menjadi bentuk slab dengan menggunakan hydroulic press pada suhu $170 \mathrm{C}$, tekanan $150 \mathrm{Kg} / \mathrm{cm}$ dengan waktu disesuaikan ketebalan. Untuk ketebalan 3-6 mm waktu pengepresan 10 menit, sedang untuk tebal $10 \mathrm{~mm}$ waktu pengepresan 15 menit.

2.2 Pengujian

Pengujian hasil penelitian dilakukan terhadap beberapa sifat fisika yang penting sesuai SII 1909-86 Sepatu Boot PVC yaitu meliputi uji tegangan tarik $100 \%$, tegangan putus, kemuluran (perpanjangan putus), perpanjangan tetap, ketahanan sobek, ketahanan kikis, ketahanan bengkuk, berat jenis dan kekerasan.

Sedangkan metode pengujian disesuaikan dengan SII 1909-86.

\section{HASIL DAN PEMBAHASAN}

Hasil penelitian berupa data hasil uji fisika kompon PVC untuk sepatu boot, yang meliputi uji tegangan putus, tegangan tarik $100 \%$, perpanjangan putus, perpanjangan tetap, ketahanan sobek, ketahanan kikis, ketahanan bengkuk, kekerasan dan berat jenis. Juga dilakukan pengamatan visual pada kenampakan kompon hasil penelitian.

Tabel 1 : Hasil uji rata-rata sifat tegangan putus $\left(\mathrm{Kg} / \mathrm{cm}^{2}\right)$

\begin{tabular}{|c|c|c|c|c|c|c|c|}
\hline \multicolumn{2}{|c|}{ Minarex } & \multicolumn{5}{|c|}{ Jumlah } & \multirow{2}{*}{$\begin{array}{l}\text { Persyaratan } \\
\text { SII 1909-86 }\end{array}$} \\
\hline Jenis & type & 5 & 10 & 15 & 20 & 25 & \\
\hline \multirow[t]{2}{*}{ A } & 2 & 93,036 & 96,548 & 102,920 & 100,327 & 96,861 & \multirow[t]{8}{*}{$\min 71,38$} \\
\hline & 3 & 80,202 & 101,742 & 103,546 & 75,449 & 94,377 & \\
\hline \multirow[t]{2}{*}{ B } & 2 & 120,683 & 127,999 & 131,160 & 119,423 & 113,656 & \\
\hline & 3 & 82,918 & 82,483 & 98,092 & 98,050 & 98,115 & \\
\hline \multirow[t]{2}{*}{$\mathrm{C}$} & 2 & 89,583 & 105,752 & 105,968 & 106,643 & 96,639 & \\
\hline & 3 & 95,359 & 86,314 & 81,853 & 87,470 & 94,475 & \\
\hline \multirow[t]{2}{*}{ D } & 2 & 100,543 & 91,914 & 83,731 & 88,345 & 86,119 & \\
\hline & 3 & 90,313 & 80,531 & 83,055 & 73,227 & 122,959 & \\
\hline
\end{tabular}


Tabel 2 : Hasil uji rata-rata sifat tegangan tarik $100 \%\left(\mathrm{Kg} / \mathrm{cm}^{2}\right)$

\begin{tabular}{c|c|c|c|c|c|c|c}
\multicolumn{2}{c|}{ Minarex } & \multicolumn{7}{c|}{ Jumlah } & Persyaratan \\
\hline Jenis & type & 5 & 10 & 15 & 20 & 25 & SII 1909-86 \\
\hline A & 2 & 45,513 & 46,054 & 46,150 & 47,081 & 46,977 & $\min 30,89$ \\
& 3 & 38,483 & 44,747 & 45,461 & 40,532 & 53,672 & \\
B & 2 & 72,102 & 74,900 & 77,631 & 78,142 & 77,406 & \\
& 3 & 51,584 & 47,203 & 42,039 & 42,827 & 44,856 & \\
C & 2 & 47,640 & 51,505 & 55,594 & 62,101 & 61,293 & \\
& 3 & 36,201 & 41,369 & 47,588 & 44,897 & 48,737 & \\
D & 2 & 50,542 & 52,184 & 58,799 & 62,415 & 66,067 & \\
& 3 & 48,695 & 48,103 & 56,221 & 53,990 & 79,386 & \\
& 3 & & & & & &
\end{tabular}

3 . Hasil uii rata-rata sifat perpanjangan putus (\%)

\begin{tabular}{|c|c|c|c|c|c|c|c|}
\hline \multicolumn{2}{|c|}{ Minarex } & \multicolumn{4}{|c|}{ Jumlah } & & \multirow{2}{*}{$\begin{array}{l}\text { Persyaratan } \\
\text { SII } 1909-86 \\
\end{array}$} \\
\hline Jenis & type & 5 & 10 & 15 & 20 & $\frac{25}{255,55}$ & \\
\hline \multirow[t]{2}{*}{$\mathrm{A}$} & 2 & 272,82 & 275,55 & 283,98 & 277,48 & $\begin{array}{l}255,55 \\
228,15\end{array}$ & $\min 300$ \\
\hline & 3 & 274,07 & 296,29 & 292,99 & 196,29 & $\begin{array}{l}228,15 \\
215,92\end{array}$ & \\
\hline \multirow[t]{2}{*}{ B } & 2 & 258,52 & 279,26 & 283,70 & 219,63 & $\begin{array}{l}215,92 \\
259,26\end{array}$ & \\
\hline & 3 & 260,00 & 253,33 & 279,85 & 270,00 & $\begin{array}{l}259,26 \\
231,85\end{array}$ & \\
\hline \multirow[t]{2}{*}{ C } & 2 & 302,59 & 297,33 & 296,29 & 283,70 & $\begin{array}{l}231,85 \\
221,48\end{array}$ & \\
\hline & 3 & 340,00 & 245,93 & 214,81 & 222,96 & $\begin{array}{l}221,48 \\
151,85\end{array}$ & \\
\hline \multirow[t]{2}{*}{$\mathrm{D}$} & 2 & 331,11 & 262,22 & 216,30 & 208,89 & $\begin{array}{l}151,85 \\
189,63\end{array}$ & \\
\hline & 3 & 304,07 & 246,29 & 230,00 & 191,85 & & \\
\hline
\end{tabular}

Tabel 4 : Hasil uji rata-rata sifat perpanjangan tetap (\%)

\begin{tabular}{c|c|c|c|c|c|c|c}
\multicolumn{2}{c|}{ Minarex } & \multicolumn{7}{c|}{ Jumlah } & $\begin{array}{l}\text { Persyaratan } \\
\text { SII 1909-86 }\end{array}$ \\
\hline Jenis & type & 5 & 10 & 15 & 20 & 25 & $\max 8,00$ \\
\hline A & 2 & 8,64 & 8,45 & 7,43 & 5,87 & 5,36 & $\max$ \\
& 3 & 6,29 & 6,64 & 4,66 & 4,52 & 4,39 & \\
B & 2 & 7,31 & 7,41 & 7,36 & 4,69 & 3,61 & \\
& 3 & 5,67 & 5,93 & 5,65 & 4,51 & 4,34 & \\
C & 2 & 7,31 & 8,53 & 7,31 & 7,35 & 6,13 & \\
& 3 & 6,93 & 7,22 & 7,87 & 6,53 & 6,05 & \\
D & 2 & 7,20 & 8,77 & 8,18 & 6,95 & 7,01 & \\
& 3 & 4,35 & 5,59 & 5,08 & 5,86 & 5,08 & \\
& 3 & & & & & &
\end{tabular}

Majalah Barang Kulit, Karet dan Plastik
Tabel 5 : Hasil uji rata-rata sifat ketahanan sobek $\left(\mathrm{Kg} / \mathrm{cm}^{2}\right)$

\begin{tabular}{c|c|c|c|c|c|c|c}
\hline \multicolumn{2}{c|}{ Minarex } & \multicolumn{7}{c|}{ Jumlah } & Persyaratan \\
SII 1909-86
\end{tabular}

Tabel 6: Hasil uji rata-rata sifat ketahanan kikis ( $\mathrm{mm} 3 / \mathrm{Kgm}$ )

\begin{tabular}{c|c|c|c|c|c|c|c}
\multicolumn{2}{c|}{ Minarex } & \multicolumn{7}{|c|}{ Jumlah } & Persyaratan \\
\cline { 1 - 6 } lenis & type & 5 & 10 & 15 & 20 & 25 & SII 1909-86 \\
\hline A & 2 & 0,464 & 0,844 & 1,378 & 1,842 & 1,725 & $\operatorname{max~} 1,00$ \\
& 3 & 2,219 & 2,268 & 2,258 & 2,362 & 2,203 & \\
B & 2 & 1,502 & 1,146 & 1,659 & 1,859 & 1,358 & \\
& 3 & 1,056 & 1,553 & 1,303 & 1,173 & 1,278 & \\
C & 2 & 0,846 & 1,375 & 1,712 & 1,471 & 1,419 & \\
& 3 & 0,845 & 0,921 & 1,040 & 0,982 & 1,386 & \\
D & 2 & 0,228 & 0,701 & 1,036 & 1,242 & 1,232 & \\
& 3 & 0,745 & 1,499 & 1,599 & 1,588 & 1,601 & \\
& 3 & & & & & &
\end{tabular}

Tabel 7: Hasil uji rata-rata sifat kekerasan (shore A)

\begin{tabular}{c|c|c|c|c|c|c|c}
\multicolumn{2}{c|}{ Minarex } & \multicolumn{7}{|c|}{ Jumlah } & Persyaratan \\
Jenis & type & 5 & 10 & 15 & 20 & 25 & SII 1909-86 \\
\hline A & 2 & 67,33 & 68,67 & 69,67 & 69,67 & 72,00 & $60-80$ \\
& 3 & 67,67 & 68,00 & 70,00 & 70,33 & 70,67 & \\
B & 2 & 67,33 & 68,00 & 70,00 & 70,67 & 74,00 & \\
& 3 & 66,00 & 69,00 & 70,00 & 70,33 & 73,67 & \\
C & 2 & 66,00 & 68,33 & 70,00 & 71,67 & 74,33 & \\
& 3 & 64,33 & 68,67 & 69,67 & 71,00 & 73,33 & \\
D & 2 & 66,67 & 70,00 & 72,33 & 74,00 & 74,33 & \\
& 3 & 68,33 & 69,33 & 72,33 & 72,67 & 75,33 & \\
& 3 & & & & & &
\end{tabular}

Vol. XII No. 23 Th. $1996 / 1997$ 
Tabel 8: Hasil uji rata-rata berat jenis $\left(\mathrm{gr} / \mathrm{cm}^{3}\right)$

\begin{tabular}{|c|c|c|c|c|c|c|c|}
\hline \multicolumn{2}{|c|}{ Minarex } & \multicolumn{5}{|c|}{ Jumlah } & \multirow{2}{*}{$\begin{array}{l}\text { Persyaratan } \\
\text { SII 1909-86 }\end{array}$} \\
\hline Jenis & type & 5 & 10 & 15 & 20 & 25 & \\
\hline \multirow[t]{2}{*}{$\mathrm{A}$} & 2 & 1,244 & 1,266 & 1,250 & 1,264 & 1,254 & \multirow[t]{8}{*}{$1,10-1,30$} \\
\hline & 3 & 1,214 & 1,234 & 1,231 & 1,253 & 1,272 & \\
\hline \multirow[t]{2}{*}{ B } & 2 & 1,224 & 1,232 & 1,243 & 1,229 & 1,224 & \\
\hline & 3 & 1,216 & 1,228 & 1,245 & 1,255 & 1,261 & \\
\hline \multirow[t]{2}{*}{ C } & 2 & 1,224 & 1,236 & 1,235 & 1,232 & 1,260 & \\
\hline & 3 & 1,234 & 1,255 & 1,261 & 1,275 & 1,274 & \\
\hline \multirow[t]{2}{*}{$\mathrm{D}$} & 2 & 1,227 & 1.217 & 1,246 & 1,254 & 1,263 & \\
\hline & 3 & 1,222 & 1,229 & 1,267 & 1,273 & 1.274 & \\
\hline
\end{tabular}

Tabel 9: Hasil uji rata-rata sifat ketahanan bengkuk untuk $150 \mathrm{Kcs}$.

\begin{tabular}{c|c|c|c|c|c|c|c}
\hline \multicolumn{2}{c|}{ Minarex } & \multicolumn{7}{c|}{ Jumlah } & Persyaratan \\
\hline Jenis & type & 5 & 10 & 15 & 20 & 25 & SII 1909-86 \\
\hline A & 2 & baik & baik & baik & retak & retak & tidak retak \\
& 3 & baik & baik & retak & retak & retak & (baik) pada \\
B & 2 & baik & retak & retak & retak & retak & 150 Kcs \\
& 3 & baik & retak & retak & retak & retak & \\
C & 2 & baik & baik & retak & retak & retak & \\
& 3 & baik & baik & baik & retak & retak & \\
D & 2 & baik & retak & retak & retak & retak & \\
& 3 & baik & retak & retak & retak & retak & \\
\end{tabular}

Dari data hasil uji sifat-sifat fisika diatas apabila dibandingkan dengan persyaratan SII 1909-86, terlihat bahwa ada 4 buah kompon yang dapat memenuhi persyaratan untuk semua sifat fisika yang dipersyaratkan yaitu kompon dengan minarex $C$ type 2, C type 3, D type 2 dan $D$ type 3 . Masing-masing dengan jumlah 5 bagian. Untuk lebih jelas dapat dilihat pada tabel dibawah ini :
Tabel 10 : Data hasil uji sifat-sifat fisika kompon sol hasil penelitian yang memenuhi persyaratan bila dibandingkan dengan SII 1909-86

\begin{tabular}{|c|c|c|c|c|c|c|}
\hline No. & Sifat Fisika & SII 1909-86 & $\begin{array}{l}\text { C type } 2 \\
\text { (5 bag) }\end{array}$ & $\begin{array}{l}\text { C type } 3 \\
(5 \mathrm{bag})\end{array}$ & $\begin{array}{l}\text { D type } 2 \\
\text { ( } 5 \text { bag) }\end{array}$ & $\begin{array}{c}\text { D type } 3 \\
(5 \text { bag })\end{array}$ \\
\hline 1. & $\begin{array}{l}\text { Tegangan putus } \\
\left(\mathrm{kg} / \mathrm{cm}^{2}\right)\end{array}$ & $\min .71,38$ & 89,583 & 95,359 & 100,543 & 90,313 \\
\hline 2. & $\begin{array}{l}\text { Tegangan tarik } \\
100 \%\left(\mathrm{~kg} / \mathrm{cm}^{2}\right)\end{array}$ & $\min .30,59$ & 47,640 & 36,201 & 50,542 & 48,695 \\
\hline 3. & $\begin{array}{l}\text { Perpanjangan putus } \\
(\%)\end{array}$ & $\min .300$ & 302,590 & 340,000 & 331,110 & 304,070 \\
\hline 4. & $\begin{array}{l}\text { Perpanjangan tetap } \\
(\%)\end{array}$ & $\max .8,00$ & 7,310 & 6,930 & 7,200 & 4,350 \\
\hline 5. & $\begin{array}{l}\text { Ketahanan sobek } \\
\left(\mathrm{Kg} / \mathrm{cm}^{2}\right)\end{array}$ & $\min .40,79$ & 45,560 & 49,870 & 51,500 & 53,460 \\
\hline 6. & $\begin{array}{l}\text { Ketahanan kikis } \\
\mathrm{mm}^{3} / \mathrm{kgm} \text { ) }\end{array}$ & $\max .1,00$ & 0,846 & 0,846 & 0,229 & 0,745 \\
\hline 7. & $\begin{array}{l}\text { Ketahanan bengkuk } \\
\text { (Kcs) }\end{array}$ & $\begin{array}{c}\text { baik } \\
\text { (tidak retak) }\end{array}$ & baik & baik & baik & baik \\
\hline 0. & Kekerasan (Shore A) & $60-80$ & 66,00 & 64,33 & 66,67 & 68,33 \\
\hline 9. & Berat jenis $\left(\mathrm{gr} / \mathrm{cm}^{3}\right)$ & $1,10-1,30$ & 1,224 & 1,234 & 1,227 & 1,223 \\
\hline
\end{tabular}

Dari data hasil uji sifat-sifat fisika yang dilakukan ternyata kompon dengan 5 bagian minarex menunjukkan hasil uji fisis yang dapat memenuhi syarat SII 1909 86.

Untuk dapat mengetahui kelakuan antar type dan jenis minarex maka dilakukan analisa secara statistik dengan menggunakan metode simple faktorial terhadap kompon dengan 5 bagian. Perhitungan dilakukan untuk setiap jenis pengujian.

Dari hasil perhitungan diperoleh :

1. Tegangan putus

Hasil perhitungan statistik untuk uji tegangan putus pada kompon dengan minarex 5 bagian adalah bahwa $F$ hitung untuk jenis minarex, type minarex dan interaksinya lebih besar dari $\mathrm{F}$ tabel sehingga perhitungan diteruskan dengan Least Significant Difference (LSD).

Dari perhitungan LSD diperoleh :

- Jenis minarex yang menunjukkan tegangan putus terbesar adalah jenis minarex $B$ dan berbeda nyata dengan yang lain.

- Type minarex yang menunjukkan tegangan putus terbesar adalah type 2 dan berbeda nyata dengan yang lain. 
Kombinasi jenis dan type minarex yang menunjukkan tegangan putus terbesar adalah kompon dengan minarex $B$ type 2 yang berbeda nyata dengan yang lain.

2. Tegangan tarik $100 \%$ minarex 5 bagian adalah bahwa $\mathrm{F}$ hitung untuk jenis minarex, type minarex dan interaksinya lebih besar dari $\mathrm{F}$ tabel sehingga perhitungan diteruskan dengan SD Dari hasil perhitungan LSD diperoleh

Jenis minarex yang menunjukkan tegargan tarik $100 \%$ terbesar adalah jenis minarex $\mathrm{B}$ dan berbeda nyata dengan yang lain.

列 2.

nteraksi jenis dan type minarex yang menunjukkan tegangan tarik $100 \%$ terbesar kompon dengan minarex $\mathrm{B}$ type 2 berbeda nyata dengan yang lain.

Perpanjangan purus

Hasil perhitungan statistik untuk uji perpanjangan putus pada kompon dengan 5 bagian adalah bahwa $F$ hitung untuk jenis minarex, type minarex dan interaksinya lebih besar dari $\mathrm{F}$ tabel dan perhitungan dapat diteruskan dengan LSD.

Perparjangan putus terbesar dicapai oleh jenis minarex $C$ dan tidak berbeda nyata dengan jenis minarex $D$

Perpanjangan putus terbesal dicapai oleh minarex type 2. Interaksi jenis dan type minarex menumjukkan perpanjangan putus terbesar adalah kompon dengan minarex C type 3 dan tidak kompon minarex D type 2 .

4. Pernanjangan tetap

Hasil perhitungan statistik untuk uji perpanjangan tetap pada kompon dengan minarex 5 bagian adalah bahwa $F$ hitung untuk jenis minarex, type minarex dan nteraksinya lebih besar dari $F$ tabel. Hasil perhitungan dengan LSD menunjukkan :

Perpanjangan tetap terkecil dicapai oleh kompon dengan penambahan minarex $D$ dan berbeda nyata dengan yang lain.

tex type 3 menunjukkan hasil uji perpanjangan tetap lebih kecil dari pada minarex type 2 .

Interaksi jenis dan type minarex yang menunjukkan perpanjangan tetap terkecil/terbaik adalah kompon dengan penambahan minarex D type 3 dan berbeda nyata dengan yang lain.

\section{Ketahanan sobek}

Hasil perhitungan statistik untuk uji ketahanan sobek pada kompon dengan minarex 5 bagian adalah :

- F hitung untuk type minarex lebih kecil dari F tabel, berarti faktor type minarex tidak mempengaruhi ketahanan sobek.

- F hitung untuk jenis minarex dan interaksinya lebih besar dari $\mathrm{F}$ tabel, dan perhitungan dilanjutkan dengan LSD.

Dari perhitungan LSD diperoleh bahwa ketahanan sobek terbesar dicapai oleh kompon dengan penambahan minarex D yang tidak berbeda nyata dengan minarex A dan minarex B. Sedangkan interaksinya ketahanan sobek terbesar dicapai oleh kompon dengan penambahan minarex A type 2 dan berbeda nyata dengan yang lain.

6. Ketahanan kikis

Hasil perhitungan statistik untuk uji ketahanan kikis pada kompon dengan minarex 5 bagian adalah bahwa $F$ hitung untuk jenis minarex, type minarex dan interaksinya lebih besar dari $\mathrm{F}$ tabel. Hasil perhitungan dengan LSD menunjukkan :

Ketahanan kikis terkecil/terbaik dicapai pada kompon dengan penambahan minarex D.

Ketahanan kikis terkecil dicapai pada kompon dengan penambahan minarex type 2.

Interaksi jenis dan type minarex menunjukkan bahwa ketahanan kikis terkecil adalah kompon dengan minarex $D$ type 2 dan berbeda nyata dengan yang lain

7. Kekerasan

Hasil perhitungan statistik untuk uji kekerasan ternyata $\mathrm{F}$ hitung untuk type minarex lebih kecil dari $\mathrm{F}$ tabel, yang berarti type minarex tidak mempengaruhi kekerasan kompon. Sedangkan untuk jenis minarex dan interaksinya perhitungan dilanjutkan dengan LSD.

Hasil perhitungan dengan LSD :

Kekerasan tertinggi dicapai oleh kompon dengan penambahan minarex $D$ type 3 dan berbeda nyata dengan yang lain.

Kekerasan terendah diperoleh pada kompon dengan penambahan minarex $\mathrm{C}$ type 3 dan berbeda nyata dengan yang lain.

8. Berat jenis

Hasil perhitungan statistik untuk uji berat jenis pada kompon dengan minarex 5 bagian adalah bahwa $\mathrm{F}$ hitung untuk type minarex ternyata lebih kecil dari $\mathrm{F}$ tabel. Hal ini berarti berat jenis tidak dipengaruhi oleh type minarex. Sedangkan $\mathrm{F}$ hitung untuk jenis minarex dan interaksinya lebih besar dari F tabel, sehingga perhitungan dilanjutkan dengan LSD. 
Hasil perhitungan LSD diperoleh :

- Berat jenis terkecil diperoleh pada kompon dengan penambahan jenis minarex $\mathrm{C}$ dan tidak berbeda nyata dengan jenis minarex $\mathrm{A}$.

- Interaksi jenis dan type minarex menunjukkan berat jenis terkecil dicapai oleh kompon dengan minarex A type 3 dan tidak berbeda nyata dengan minarex B type 3, minarex $C$ type 2 dan minarex $C$ type 3 .

9. Ketahanan bengkuk

Pada uji ketahanan bengkuk terlihat bahwa kompon dengan pemakaian minarex 5 bain untuk semua jenis minarex menunjukkan tidak retak (baik) pada 150 Kcs, sesuai dengan persyaratan SII 1909-86 "Sepatu boot PVC".

\section{KESIMPULAN}

Dari hasil penelitian dan pergamatan yang dilakukan maka dapat disimpulkan bahwa :

1. Terdapat 4 buah kompon PVC yang memenuhi persyaratan SII 1909-86 "Sepatu Boot PVC", yaitu kompon dengan minarex C type 2, minarex C type 3, minarex $D$ type 2 dan minarex $D$ type 3, masing-masing pada 5 bagian minarex

2 Untuk jenis minarex A dan minarex B tidak dapat digunakan sebagai plasticizer pada kompon PVC untuk sepatu boot, karena kompon PVC yang dihasilkan tidak memenuhi persyaratan SII 1909-86, terutama pada sifat perpanjangan putus (kemuluran) dan ketahanan kikis.

\section{DAFTAR PUSTAKA}

1. ISO 4643 - 1980 : Plastics Moulded Footwear-Polyvinyl Chloride Industrial Boot Specification.

2. J. Kern Sears \& Joseph. R.D. : The Technology of Plasticizer, John Wiley \& Sons New York, 1982

3. SII 1909-86: Sepatu Boot dari PVC

4. Anonym : PVC additive, CIBA Geigy 